\title{
ILHAS DE CALOR EM VITÓRIA DA CONQUISTA - BA: IDENTIFICAÇÃO E PROPOSTA PARA CRIAÇÃO DE ÁREAS VERDES
}

\author{
Kaique Brito Silva* \\ Neylor Alves Calasans Rego ${ }^{* *}$ \\ Karine Orrico Góes * \\ Giovanna Porto Santos ${ }^{* * * * *}$ \\ Pollyanna Alves Dias Costa*****
}

RESUMO: Temperatura elevada em cidades surge como mais um agravante resultante das problemáticas ambientais. Atualmente, cientistas de todo o mundo têm direcionado esforços no sentido de compreender os aspectos que contribuem para o aumento da temperatura urbana e seus efeitos. Desta forma, este estudo teve por objetivo identificar as ilhas de calor na área urbana do município de Vitória da Conquista - Bahia. O procedimento metodológico empregado para identificação das ilhas de calor foi por meio da utilização dos dados do sensor termal dos satélites LandsatTM 5 e 8, onde, posteriormente foram realizadas as correções atmosféricas e conversões em unidades de temperatura dos níveis de tons de cinza gerados pelo satélite para valores de temperatura da superfície. Os resultados mostraram variações de temperatura no perímetro urbano com identificação de sete ilhas de calor, cujos locais são caracterizados pela maior concentração de área pavimentada e ausência de vegetação. Foram identificadas dez áreas potenciais para a implementação de áreas verdes de forma a melhorar as condições de temperatura nos pontos quentes identificados. Estes resultados poderão subsidiar o planejamento urbano como suporte à tomada de decisões e na construção de estratégias no sentido de minimizar o desconforto térmico.

PALAVRAS-CHAVE: Temperatura; Clima urbano; Áreas verdes.

\footnotetext{
Mestre em Desenvolvimento Regional e Meio Ambiente pela Universidade Estadual de Santa Cruz, Brasil. E-mail: kbritofb96@hotmail.com

** Doutor em Engenharia e Água e Solos (Pennsylvannia State Univerty), docente Pleno do Departamento de Ciências Agrárias e Ambientais da Universidade Estadual de Santa Cruz, Brasil.

*** Doutora em Desenvolvimento e Meio Ambiente (PRODEMA) e docente titular do Departamento de Ciências da Saúde da Universidade Estadual de Santa Cruz, Brasil.

**** Doutora em Desenvolvimento e Meio Ambiente (PRODEMA) e docente titular do Departamento de Ciências da Saúde da Universidade Estadual de Santa Cruz, Brasil

***** Doutora em Meio Ambiente (UFC) e docente assistente do Departamento de Ciências Agrárias e Ambientais da Universidade Estadual de Santa Cruz, Brasil.
} 


\title{
HEAT ISLETS IN VITÓRIA DA CONQUISTA, BRAZIL: IDENTIFICATION AND SUGGESTIONS FOR THE ESTABLISHMENT OF GREEN AREAS
}

\begin{abstract}
High temperatures in cities are the result of critical environmental issues. Scientists all over the world have made every effort to understand the factors that increase temperature and its effects in towns and cities. Current study analyzes heat islets within the city area of Vitória da Conquista BA Brazil. Heat-identification Methodology comprised thermal sensor data from satellites LandsatTM 5 and 8, with atmospheric corrections and conversions in temperature units in grey tones produced by satellite for surface temperature rates. Results showed temperature variations within the city area comprising seven heat islets featuring site characterized by high asphalt area rate and lack of greenery. Ten potential areas were identified for the implementation of green areas to improve temperature conditions in the identified hot spots. Results may be a help in urban planning for decision-taking and for the construction of strategies to minimize thermal discomfort.
\end{abstract}

KEY WORDS: Temperature; Urban climate; Green areas.

\section{INTRODUÇÃO}

Atualmente 1,5 bilhão de pessoas habitam em áreas consideradas urbanas, majoritariamente nas grandes cidades. Essa ocorrência corresponde a $18 \%$ da população mundial. De forma geral, a cidade é considerada como a estância inicial para o estudo de várias áreas do conhecimento que visam o homem como um objeto de estudo, pois "a realidade da vida é o aglomerado urbano" (PIMENTEL; BURGS, 2015).

Entretanto, esta realidade é categoricamente vista como um reduto de problemas ambientais pelo fato de que o homem transcendeu a natureza original do espaço geográfico, promovendo traços antropizados que produzem mudanças no lugar e, consequentemente, diversos impactos sobre a qualidade de vida da população in locus.

Os impactos da urbanização sobre a qualidade de ar é uma das inúmeras problemáticas existentes e, atualmente, têm sido intensamente trabalhados pela 
ciência climatológica nos últimos 20 anos. Hoje, a população está exposta aos índices de poluição do ar maiores do que o que recomendado pela Organização Mundial da Saúde (OMS), e a esta situação são atribuídas aproximadamente 400 mil mortes por ano (KOKEN et al., 2003).

Reuniões governamentais com foco ambiental desde a realizada em Estocolmo em 1972, juntamente com os atuais relatórios do IPCC sobre mudanças climáticas mundiais, fomentam os estudos de alterações macro e microclimáticas em diversas regiões. A composição heterogênea da atmosfera intraurbana derivada de atividades poluentes emerge como potencial prejudicial à qualidade ambiental e saúde humana.

A temperatura da superfície e do ar na faixa dos 02 metros acima do solo tem sido objeto de estudo de diversos trabalhos. Carnahan e Larson (1990), Katsouyanni (1993), Harvell (2002), Kuhn et al. (2002) e Garske et al. (2013) discutem sobre saúde ambiental urbana; Koken et al. (2003) correlacionam a temperatura do ar urbano com poluição atmosférica; e Laaidi (2012) discute a poluição atmosférica urbana como sendo responsável pelo risco de morbidade.

Dessa forma, o atual pivô das discussões sobre a elevação da temperatura em ambientes urbanos são os fenômenos conhecidos como as ilhas de calor. Esse conceito de ilha surge no intuito de esclarecer a ocorrência de locais estritamente urbanos de temperatura elevada presentes numa paisagem natural de temperatura homogênea. A formação do calor é diretamente influenciada pela presença de diversos fatores, tais como a verticalização, o albedo, a ausência de áreas verdes e a intensa circulação de veículos (SANTANA, 2014).

A ocorrência de ilhas de calor se intensifica espacialmente nos centros dos grandes aglomerados urbanos, pois ali os materiais de baixa reflexão (albedo) se encontram em maiores quantidades; à medida que se observam em locais mais afastados do centro a tendência é de diminuição da temperatura.

Além destas, há diversas outras características que influenciam na formação e intensidade das ilhas de calor como posição no globo terrestre, topografia, geomorfologia, condições meteorológicas do dia, a densidade populacional, a umidade relativa do ar, fenômeno de continentalidade, órbita solar, dentre outros (CARNAHAM; LARSON, 1990; SANTANA, 2014). 
Dessa forma, diversas pesquisas não só contemplam a temperatura de superfície, mas focam o seu objeto de estudo estritamente para a ocorrência de ilhas de calor. Lombardo (1985) estudou a formação e consequências de ilhas de calor em São Paulo; Kimura e Takashi (1991) estudaram os efeitos antropogênicos na formação de pontos quentes na cidade de Tókio; Nichol (1994) estudou o aquecimento do microclima urbano a partir de construções na cidade de Singapura; Mihalakakou e Santamouris (2004), na Grécia, fizeram simulações de ocorrências de ilhas de calor em climas mediterrâneos; Van e Bao (2010) realizaram um estudo sobre o impacto de desenvolvimento urbano na elevação de temperaturas de superfície utilizando sensoriamento remoto na cidade de Ho Chi Minh, Vietnã; e Sousa (2012) utilizou dados de temperatura terrestre para identificar ilhas de calor na cidade de Goiânia.

Para detectar estes "pontos quentes" de temperaturas, existem possibilidades de monitoramento por meio de estações meteorológicas implantadas no aglomerado urbano. Mas, nos últimos 30 anos, surgiram ferramentas relacionadas à prospecção de dados da paisagem atmosférica, com custos mais acessíveis comparados ao monitoramento in locus. A detecção de ilhas de calor atualmente é possível por meio do sensoriamento remoto, resultante do lançamento de satélites orbitais Landsat TM, onde se encontram acoplados sensores termais responsáveis pela obtenção de dados da superfície terrestre em infravermelho.

Conseguinte a obtenção dessas imagens, as ferramentas adequadas para o processamento de dados termais são os SIG's (Sistemas de Informações Geográficas). Nesse ambiente é possível visualizar, corrigir e recortar imagens termais georreferenciadas e sobrepor em áreas de estudos desejadas, originando representações espaciais (mapas e cartogramas) de concentrações calorosas. Além de ilhas de calor urbanas tal método é empregado no estudo de focos e deslocamento de queimadas (BOSCHETTI, 2015; PADILLA, 2015).

\section{1 ÁREAS VERDES}

A criação de buffes e layers de sobreposições nos SIG's permite também projetar a criação de alternativas para reduzir os efeitos de elevadas temperaturas em locais pontuais. Nessa concepção, as áreas verdes emergem como a principal resolução de ocorrências de pontos quentes presentes nos grandes centros. 
Diversos autores discutem a definição de áreas verdes. Para Cavalheiro et al. (1992), as áreas verdes são espaços com vegetação que foram projetadas juntamente com os equipamentos urbanos. São parques, jardins, alamedas, bosques, praças de esportes, playgrounds, balneários e margens de rios, lagoa e represas. Milano (1995) conceitua áreas verdes como áreas livres na cidade com características predominantemente natural, independente do porte da vegetação. Já Guzzo (2006) afirma que áreas verdes são aquelas onde há o predomínio de vegetação arbórea no meio urbano, ideal quando juntamente a essa área estão presentes também corpos d'água.

Os diversos benefícios ambientais e sociais que as áreas verdes proporcionam são a diminuição da poluição, redução do albedo (reflexão das ondas curtas solares), aumento da evapotranspiração, produção de sombras, regulamentação da umidade do ar e da temperatura, conforto térmico, fertilidade do solo, proteção contra erosão e assoreamento de rios urbanos, redução dos níveis de ruídos e amortecimento do barulho das cidades (LOBODA; ANGELIS, 2005).

A cidade de Vitória da Conquista, área de estudo do trabalho, é mais um reduto urbano caracterizado pelo crescimento socioeconômico acelerado, e os retratos desse processo é notado pelo surgimento de uma área urbana extensa e processos de verticalização em zonas de valoração imobiliária. Entretanto, o desenvolvimento não contempla, por meio de estudos prévios, a importância da presença de áreas verdes para mitigação de fenômenos como as ilhas de calor e poluição atmosférica (LAAIDI, 2012).

Dessa forma, o objetivo deste trabalho foi utilizar ferramentas de geoprocessamento para estudos geoambientais que permitem a execução de um método de identificação de pontos quentes urbanos em relação às localidades no entorno. Em seguida, foi proposta a construção de novas áreas verdes relativamente próximas às ilhas de calor no intuito de mitigar seus impactos negativos. Assim, visualizar o fenômeno e no mesmo ambiente digital (SIG) propor uma medida de mitigação sugere uma eficácia na resolução de problemáticas ambientais urbanas. 


\section{METODOLOGIA}

\section{1 ÁREA DE ESTUDO}

A área de estudo do trabalho é a cidade de Vitória da Conquista (Figura 1). Localizada na região Sul do Estado da Bahia, encontra-se cerca de $510 \mathrm{~km}$ de distância da capital Salvador. O município detém um território de 3.204 km², com aproximadamente 346.000 habitantes na sede e mais 10.000 divididos em outros 17 distritos (IBGE, 2010). Apresenta uma densidade demográfica de 105,17 hab/km², o que a promove a terceira cidade mais populosa da Bahia, com emancipação política no ano de 1840 (175 anos).

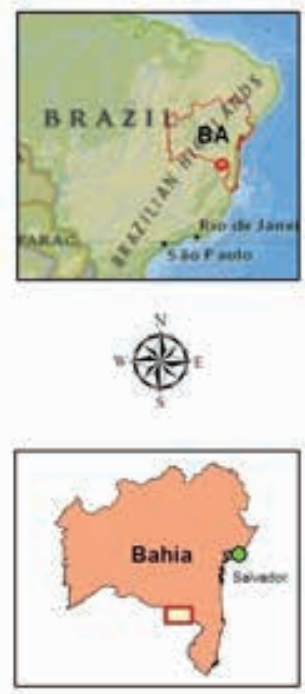

Municipios

Capital do estado

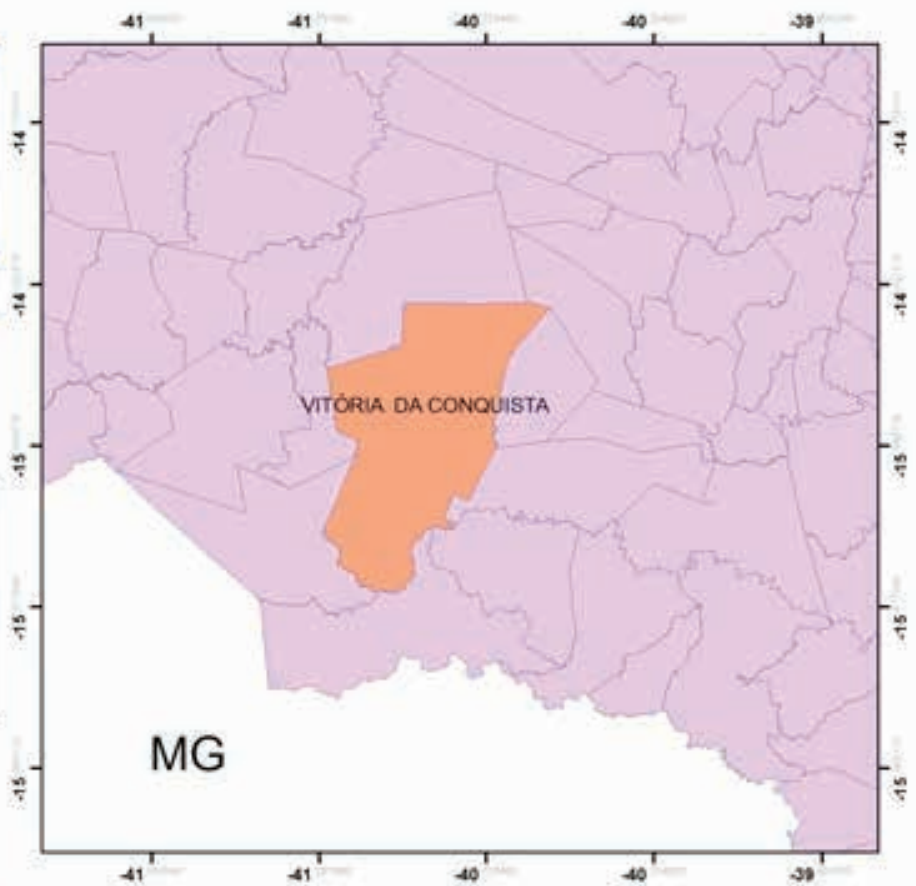

0

Figura 1. Localização do município de Vitória da Conquista e sua área urbana 
Inserida no Planato da Conquista adjacente a Serra do Peri-Peri $(1.100 \mathrm{~m}$ de altitude, Figura 2), a tipologia climática na região, de acordo com a classificação de Köppen (1948), tem a predominância do clima tipo Cwb (tropical de altitude), com médias anuais de temperatura variando entre $17,8^{\circ} \mathrm{C}$ e $24^{\circ} \mathrm{C}$, com duas estações bem definidas, isto é, primavera e verão quentes e chuvosos, e outono e inverno mais secos e frios. O mês mais quente é março, com temperatura média de $22,0^{\circ} \mathrm{C}$, enquanto o mês mais frio é julho, com média de $17,8^{\circ} \mathrm{C}$, registrando temperaturas inferiores a $10^{\circ} \mathrm{C}$ em alguns dias do inverno. A pluviosidade média anual é de 734 mm, com estação seca de maio a setembro (SOARES, 2009).

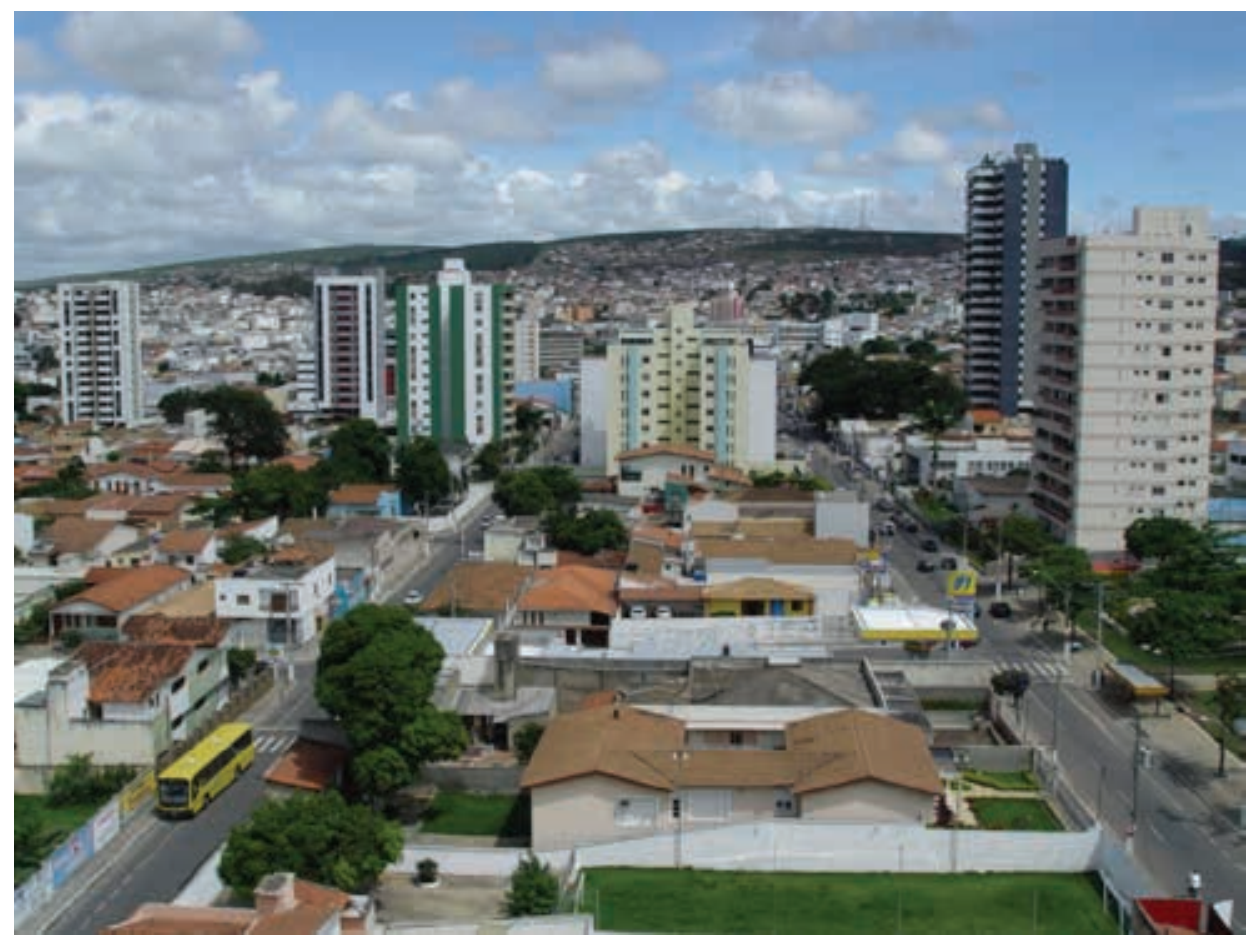

Figura 2. Área urbana com a serra do Peri-Peri ao fundo

Com o crescimento da cidade, atualmente existem 20 bairros resultantes de um processo geográfico classificado como inchaço urbano. Em bairros de alto valor imobiliário, o fenômeno de verticalização (edificações) tem se intensificado desde a primeira década do presente século, promovendo uma paisagem estritamente 
artificializada. Em contrapartida, o número de áreas verdes efetivas (14 praças no total) ainda é relativamente baixo, resultando numa ocorrência de $33 \mathrm{~m}^{2}$ por $\mathrm{km}^{2}$ da cidade.

\subsection{TEMPERATURA A PARTIR DE SENSOR TERMAL}

A obtenção e das ilhas de calor foi realizada por meio de dados do sensor termal dos satélites Landsat TM 5 e 8, respectivamente as bandas 6 e 11, horários diurnos do ponto 71 da órbitas 216, entre os anos de 2011 e 2014 (Quadro 1). As imagens Landsat 5 estão disponíveis no site do Instituto Nacional de Pesquisas Espaciais - Inpe, e imagens Landsat 8 no serviço cartointerativo do Serviço Geológico Americano - USGS.

Quadro 1. Metadados das imagens de satélite

\begin{tabular}{|c|c|c|}
\hline \multicolumn{3}{|c|}{ Órbitas } \\
\hline Sensores & Datas & Horário \\
\hline Landsat 5 & $28 / 06 / 2011$ & $12: 25$ \\
\hline Landsat 8 & $21 / 04 / 2013$ & $12: 41$ \\
\hline Landsat 8 & $24 / 04 / 2014$ & $12: 43$ \\
\hline
\end{tabular}

A banda termal tem somente a função de captar dados de temperatura, e apresenta sensibilidade aos fenômenos relativos aos contrastes térmicos, servindo para detectar propriedades termais sobre as rochas, solos, vegetação e água.

Os cruzamentos das informações obtidas remotamente produzem uma imagem termal baseada na presença de ondas em infravermelho na superfície terrestre, com uma resolução espacial de $120 \mathrm{~m}$. Dessa forma, a temperatura corresponde à superfície de determinado local em órbita do satélite. Esse conjunto de respostas espectrais é reproduzido em imagens de satélites georreferenciadas, ou seja, em arquivos rasterizados com os valores termais representados em tons de cinza. 


\subsection{GEOPROCESSAMENTO DOS DADOS}

Obtidos os dados termais, tornou-se necessária a realização de correções atmosféricas e conversões em unidades convencionais de temperatura, considerando que existem diversas variáveis no sensoriamento remoto que podem descaracterizar a realidade da paisagem. Tais variáveis são elementos atmosféricos como nuvens, inclinações orbitais, raios de tempestades solares, sedimentos em suspensão e gases de combustões.

Em primeiro momento, foram realizadas correções atmosféricas no software IDRISI Taiga. Com as imagens brutas importadas, foram executados os módulos "ATMOSC" (que automaticamente corrige algumas influências atmosféricas como gases, nuvens, comprimento de ondas etc.). Posteriormente, aplicou-se a ferramenta "THERMAL", a qual converte os tons de cinza da imagem tratada atmosfericamente para valores em radiância espectral (L $\lambda$ ).

Em seguida, as imagens corrigidas foram manipuladas no software ArcGis 10.1, sendo realizada a conversão dos valores em radiância espectral para temperatura em graus Kelvin, unidade de temperatura base na linguagem de SIG's. Essa conversão é possível a partir da Equação 1 desenvolvida por Markham e Barker (1986).

$$
T=\frac{K 2}{\ln \left(1+\frac{K 1}{L \lambda}\right)}
$$

em que:

$\mathrm{T}=$ temperatura em Kelvin

K2 = Calibração constante em Kelvin

$\mathrm{K} 1=$ Calibração constante

$\mathrm{L}=$ radiância espectral do sensor

Os dados de calibração das constantes de calibração (Quadro 2) da Equação 1 estão indexados nos parâmetros da imagens TM (arquivo.txt da imagem), a seguir: 
Quadro 2. Atributos de calibração das imagens

\begin{tabular}{|c|c|c|}
\hline \multicolumn{3}{|c|}{ Constantes de calibração TM termal } \\
\hline Unidades & $\mathrm{W} /\left(\mathrm{m}^{2} . \mathrm{sr} . \mu \mathrm{m}\right)$ & Kelvin \\
\hline Constante & $\mathrm{K} 1$ & $\mathrm{~K} 2$ \\
\hline Landsat5 & 671.62 & 1284.30 \\
\hline Landsat8 & 774.86 & 1321.08 \\
\hline
\end{tabular}

No ArcGis 10.1, utilizou a ferramenta Tollbox> "conversiontolls Landsat image" que em sua aplicação equaciona as fórmulas de conversão definidas por Markham e Barker (1986) e de graus Kelvin para Celsius, com a legenda final das imagens em graus Celsius $\left({ }^{\circ} \mathrm{C}\right)$.

As imagens LandSat apresentam uma cobertura da superfície de aproximadamente $32.000 \mathrm{~km}^{2}$, sendo considerada então uma cobertura de escala regional. O grande empecilho, em geral, para o uso destas imagens é a cobertura de nuvens maior do que $25 \%$. Não havendo tal problema, basta apenas realizar um recorte espacial e aplicá-lo.

Para melhor velocidade no processamento dos dados termais, foi realizada a extração da área estudada da imagem inicial, obtendo assim um polígono de recorte correspondente a área urbana de Vitória da Conquista (cerca de 170 km²), concentrado as informações de temperatura apenas para área de estudo. Essa extração de área foi realizada no ArcGis 9.3 utilizando a Tollbox"Spatial Analyst>Extract by mask". Sobre as imagens termais foram lançadas camadas ("Layer" no ArcMap) dos arruamentos e das 14 áreas verdes efetivas da cidade identificados através da lista de praças públicas listadas pela prefeitura de Vitória da Conquista (VITÓRIA DA CONQUISTA, 2000).

\subsection{PROPOSTA DE NOVAS ÁREAS VERDES}

A prospecção de áreas com potencial a serem futuros ambientes arborizados foi realizada no momento seguinte a identificação das ilhas de calor urbana de Vitória da Conquista. Observaram-se trabalhos como os de Burgess et al (1988) e Carrus et al (2004) que descrevem a importância de correlação espacial aplicada entre os "botspots" e locais com potencial para criação de áreas verdes. Esse arranjo 
é montado no sentido de tornar as novas áreas próximas às ilhas de calor, bem como também favorecer a presença permanente de pessoas ou circulação de veículos.

Essa preocupação em relação à proximidade das áreas verdes com os atores urbanos é levantada também por Vieira (2004). Para o autor o sucesso de uma área verde é notado quando ela permeia por quatro funções que podem ser vistas na Figura 3.

\section{Função Social}

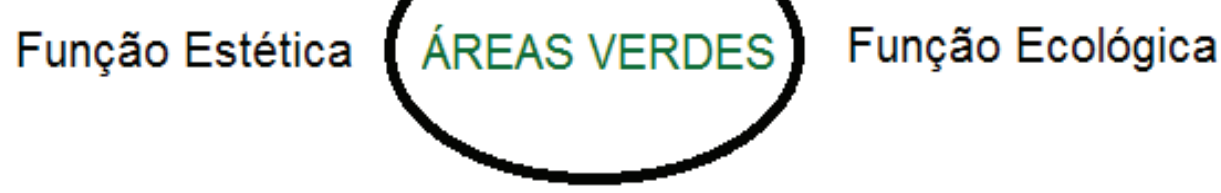

\section{Função Educativa}

Figura 3. Abrangência ideal de uma área verde

A função social de uma área verde é a possibilidade de socialização entre os indivíduos em sua proximidade, sem hierarquização. É um local para lazer, esporte e outros entretenimentos. Cabe frisar nesse momento a importância das árvores no sentido de "filtrar" poluentes responsáveis por doenças respiratórias.

A função estética se dá no sentido de compor uma beleza cênica para a cidade. As espécies de árvores, os bosques e sua posição geográfica devem evidenciar essa imponência na paisagem.

A função educativa é a utilização desses espaços para promover conhecimento sobre a importância do meio natural para o equilíbrio ambiental em todas as escalas geográficas. Atividades realizadas por escolas de educação infantil são as mais contempladas nessa perspectiva.

Por fim, a função ecológica é a que contempla a importância de uma área verde no suporte ambiental da área a qual está inserida. A contribuição para mitigar os impactos à atmosfera são os mais relevantes. Dependendo de sua dimensão e posição na cidade, favorece também a presença e circulação de espécies da fauna e 
colonização de espécies da flora.

Essa concepção também abrange o fato de que nem sempre é possível encontrar locais propícios à arborização sob as ilhas de calor, mas seguindo a circulação atmosférica, locais relativamente próximos podem amenizar o fenômeno. Dessa forma, observando a metodologia apresentada por Vieira (2004), optou-se pela identificação e escolha de largos, terrenos públicos, praças e parques abandonados e não arborizados relativamente próximos aos pontos de temperaturas agudizadas.

Nessa etapa do trabalho, realizaram-se quatro campanhas de campo no intuito de georreferenciar os locais propostos, utilizando os seguintes equipamentos: 1) aparelhos GPS's Garmim Oregon 650 com precisão geodésica de 2 m; 2) mapas com as ilhas identificadas para reconhecimento ambiental da área, visando os locais ideais descritos por Carrus (2013).

\section{RESULTADOS E DISCUSSÕES}

\subsection{ILHAS DE CALOR}

A sobreposição final das imagens de 2011, 2013 e 2014 permitiu a identificação de sete pontos de temperaturas elevadas, ou seja, sete ilhas urbanas de calor. Esse conceito de ilha é derivado da noção de um ponto isolado cercado por uma paisagem homogênea, e é notado na Figura 4. As imagens apresentaram pontos de calor em comum, vistos com mais nitidez nos setores S1 e S2. Dessa forma, observou-se um padrão na ocorrência de temperaturas pela configuração ambiental dos locais. 


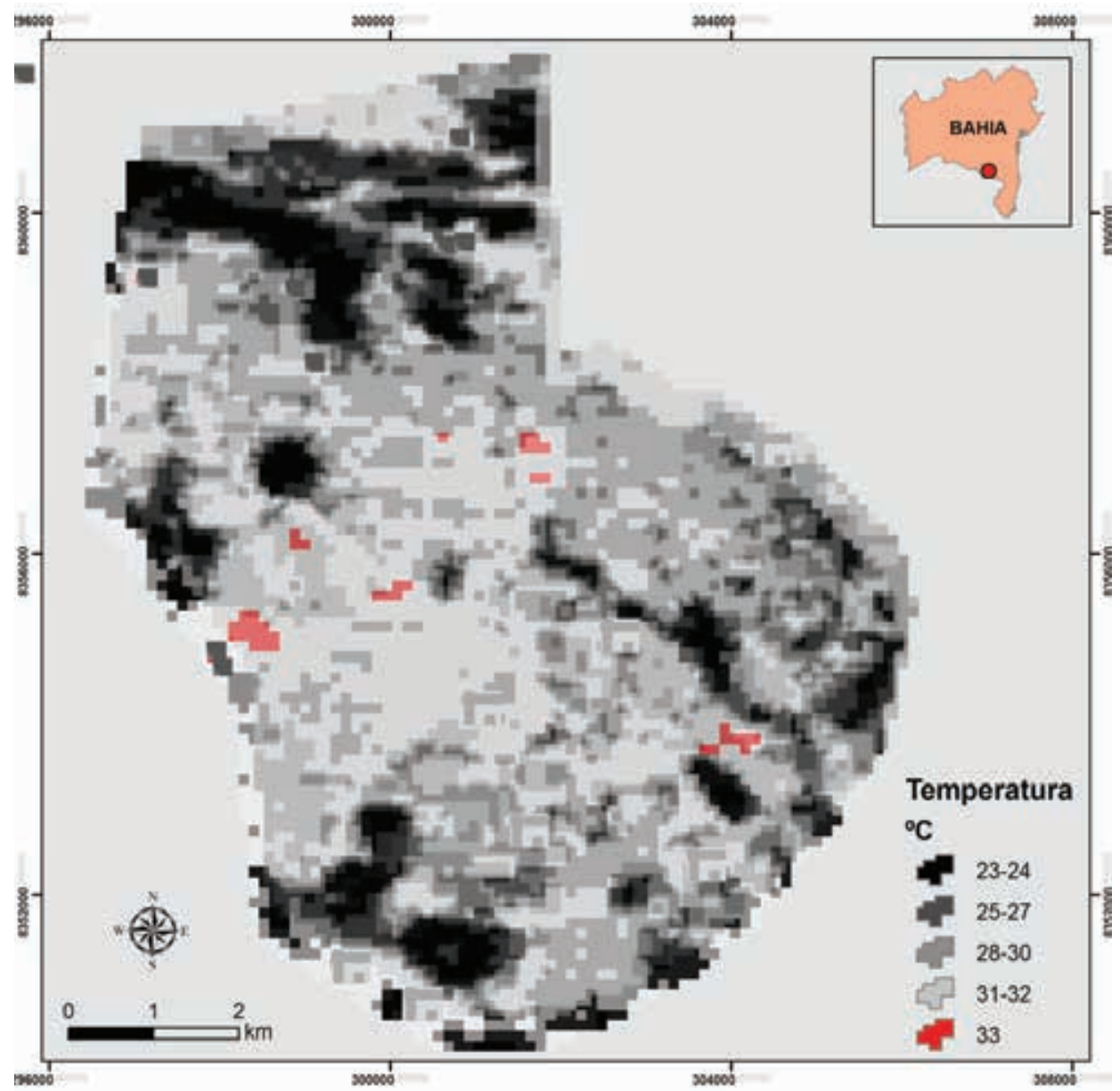

Figura 4. Ilhas de calor urbanas em Vitória da Conquista

Como mostra a Figura 4, as temperaturas elevadas diferem da temperatura ambiental padrão, ambas representadas pelas colorações de intensidade calórica seguindo do negro até o vermelho, numa escala de ${ }^{\circ} \mathrm{C}$. Esse comportamento térmico estáintrinsecamente atreladoà paisagem local, a qual se sabe ser de caráter estritamente urbano. Corroborando com este fenômeno existem trabalhos (CIFUENTES, 2001; BARCZAK; DUARTE, 2012) que alertam para os impactos ambientais negativos de ambientes totalmente desprovidos de elementos que restabeleçam a composição atmosférica natural das ilhas de calor, tratando-se principalmente de circulação de 
ventos, retenção hídrica e evapotranspiração. Concomitantemente, implantações de asfalto e construções de coloração escura, absolvem todos os comprimentos de ondas do espectro eletromagnético (radiação solar) como também o infravermelho, que naturalmente é percebido e reproduzido na forma de calor sensível.

As ilhas de calor apresentaram ocorrências regionalizadas e podem ser observados quatro agrupamentos em bairros com alto índice predial (construções), representados como S1, S2 e S3 (Figuras 5 e 6).

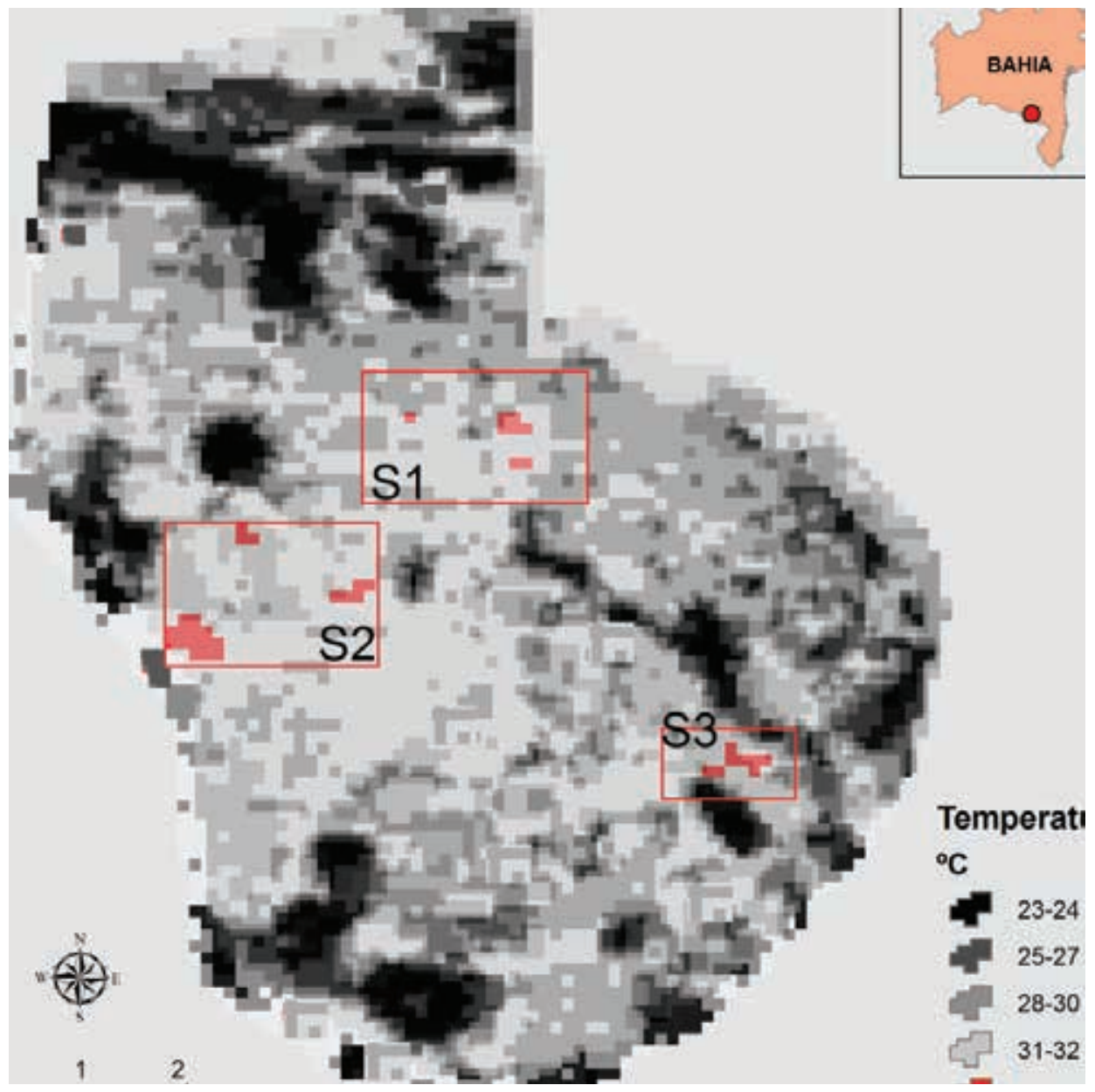

Figura 5. Setores delimitados 


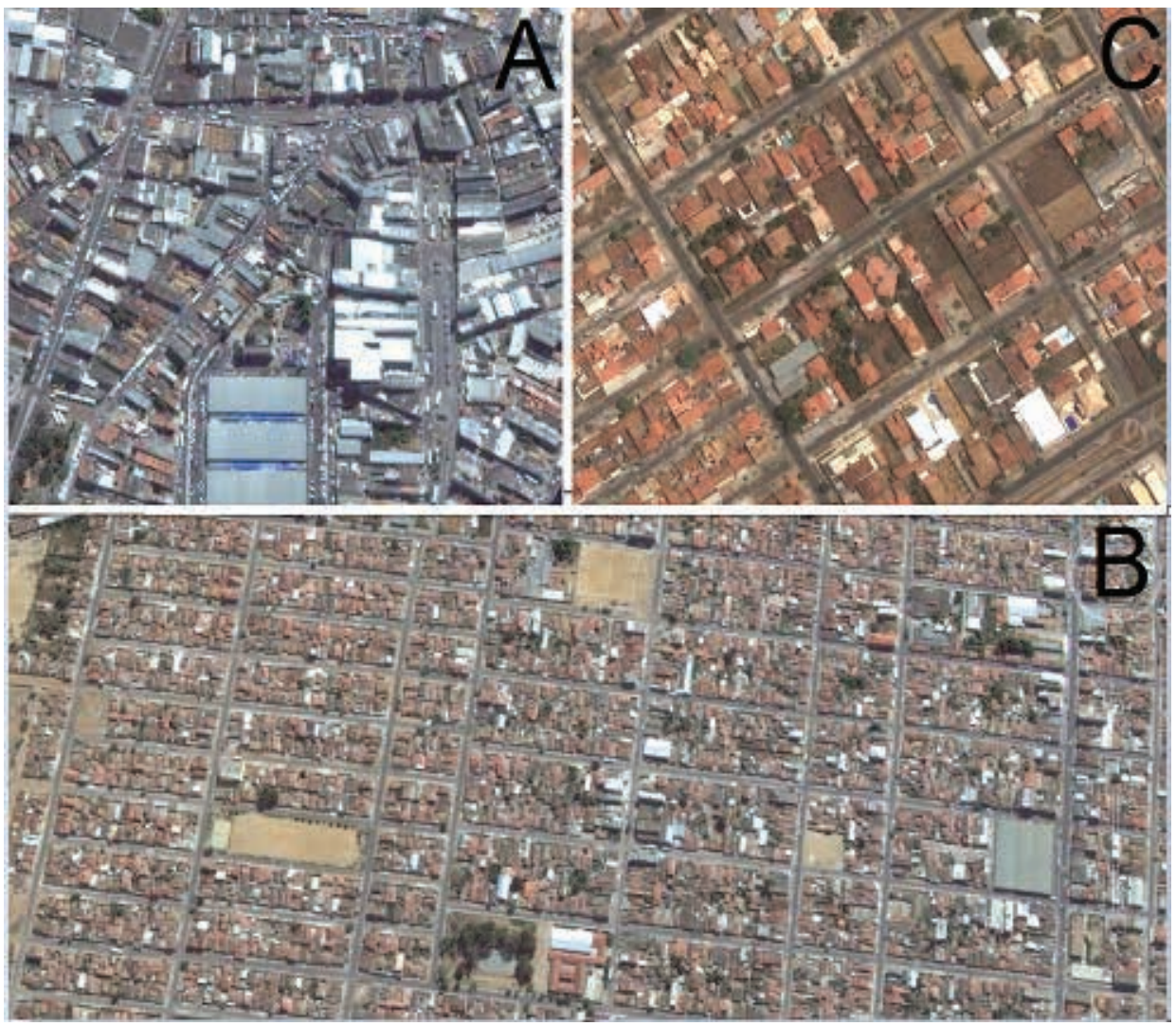

Figura 6. Paisagem dos agrupamentos: a) $S 1$; b) S2; c) S3

O agrupamento S1 ocorre na zona central da cidade, especificamente nos bairros Centro e Recreio. Nessa região da cidade, ocorre um condensado de construções com ausência de áreas verdes efetivas. A organização assimétrica dos arruamentos lineares não contemplou construções de praças e/ou parques e não existem corpos hídricos perpassando o local. Isso explica a ocorrência de ilhas de calor na zona. Além disso, o agrupamento S1 é uma ocorrência sobreposta ao centro financeiro da cidade, na área comercial Ceasa $\mathrm{O}$ fenômeno de verticalização do espaço é presente nessa área, o que é responsável pela formação dos denominados "cânions urbanos". Nesse tipo de formação caracterizado por grandes edificações, a circulação do ar é baixa e a dispersão de poluentes atmosféricos, em destaque o $\mathrm{CO}_{2}$ resultante da grande circulação veicular que ocorre lentamente. O único corpo 
hídrico que perpassa o setor é um riacho canalizado. Atrelado a isso, o aquecimento do solo devido ao asfalto e o albedo define a ocorrência de ilhas de calor na zona. Considerando que o tráfego de pessoas também é grande nessa área, nasce um apelo para inferências acerca de calor e saúde populacional.

No agrupamento $\$ 2$ (que contempla os bairros Brasil e Bateias), as grandes matrizes da paisagem são quarteirões residenciais e lotes não ocupados utilizados como estacionamentos e pátios rodoviários. Encontram-se também extensas coberturas de prédios comerciais em amianto e alumínio, que retém calor sensível em sua estrutura. Essa última característica é potencialmente condicionante para a ocorrência de temperatura elevada na zona.

Nesse momento vale explanar que a composição geomorfológica do município influencia diretamente na concentração de calor sensível pela redução da circulação de ar por se tratar de uma cidade estabelecida no sopé da serra do Peri-Peri e adjacente a um vale fluvial, do rio Verruga. A circulação de ventos aqui (comparada com áreas mais altas da área urbana) é 45\% menor. A amplitude altimétrica entre o setor S2 (região mais baixa da cidade) e os bairros periféricos mais altos chega a $118 \mathrm{~m}$. Como nos outros pontos, a ausência total de vegetação e corpos hídricos influenciam de forma acelerada na formação de pontos quentes de temperatura.

Por fim, o setor S3 é caracterizado também por construções residenciais. Localiza-se no bairro Candeias, classe média alta. Aqui não há processos de verticalização instalados, mesmo sendo uma área comercial. Há intensos fluxos de pessoas e tráfego de automóveis, sendo centroide para a circulação de carros e ônibus pela logística de supermercados e faculdades. Observa-se uma intensa pavimentação asfáltica, bem como a ausência total de áreas verdes e corpos hídricos.

Observando os valores térmicos numa perspectiva geográfica de direção NO $>$ NE entre os setores $S 1$ e S2, observa-se um padrão no aumento da temperatura conforme há proximidade com a área central da cidade. Nas zonas periféricas, ainda existem diversos lotes e bairros com um índice predial relativamente baixo comparado ao centro. Esses espaços "vazios" geralmente são terrenos baldios, percebidos pelos sensores termais como locais de temperaturas mais amenas. 


\subsection{NOVAS ÁREAS VERDES}

Como exposto, existem atualmente 14 áreas verdes em Vitória da Conquista, enquadradas nas definições de Cavalheiro et al. (1992), Milano (1995) e Guzzo (2006) (Figura 5). Restringem-se a praças de bairros e alguns bosques no centro da cidade, por exemplo, o largo Tancredo Neves, parque da Cidade e parque das Bateias. Historicamente, tais pontos sempre foram retratados como locais de lazer e beleza cênica, não como áreas pensadas no intuito de amenizar efeitos de perturbação urbana, mas que de certa forma contribuem para a mitigação.

Visando locais ideais para a instalação de áreas verdes com as funções sociais, estética, educativa e ecológica, foram identificados dez locais com susceptibilidade à implantação de obras de arborização, seguindo os critérios apresentados na metodologia. Houve também preocupação em identificar áreas relativamente próximas às ilhas de calor observadas em campo (Figura 7).

Entretanto, essa proximidade foi comprometida pelas características urbanas dos locais visitados. Tratou-se da eventualidade de não existirem zonas com potencial para áreas verdes, ou, como no agrupamento $\mathrm{S} 2$, dispor apenas de um largo relativamente distante dos pontos quentes. Mesmo assim, optou-se em prospectar e propor criação de áreas verdes em zonas adjacentes considerando a grande população dos bairros próximos, a presença de escolas e eventuais ganhos paisagísticos de sua criação.

A zona S1 apresentou três áreas com potencial para criação de áreas verdes, especificamente no entorno aos pontos de temperatura elevada (Figura 4). Observaram-se terrenos no entorno ao principal comércio da cidade, o Ceasa. No sentido de contemplar a proximidade da área verde com ilha de calor, circulação de pessoas e veículos, apresentou-se como satisfatório o local proposto visando à função social e ecológica apresentadas por Vieira (2004).

A zona S2 apresentou cinco áreas com potencial à criação de uma nova área verde. Mesmo não havendo sobreposição espacial de tais áreas com as ilhas de calor, quando criadas, essas zonas podem diminuir as ilhas de calor considerando uma microcirculação atmosférica auxiliada pelo riacho próximo, frisando que evaporação e evapotranspiração são processos mitigadores. 
Por fim, na zona S3 também se observou otimização no processo de identificação de áreas em potencial, tendo em vista que as mesmas estão adjacentes às ilhas de calor da área. Pela presença desses espaços em locais de exata sobreposição de ocorrências de ilhas de calor, é considerado um resultado satisfatório na implantação do método atrelado às condições de instalação no reduto urbano.

Considerando também as funções ideais de uma área verde, os locais identificados contemplam sobreposição às ilhas de calor, função social para a circulação de pessoas, a função ecológica visando a veículos e seus poluentes, e por se tratar da principal entrada da cidade, terá função estética numa possível criação.

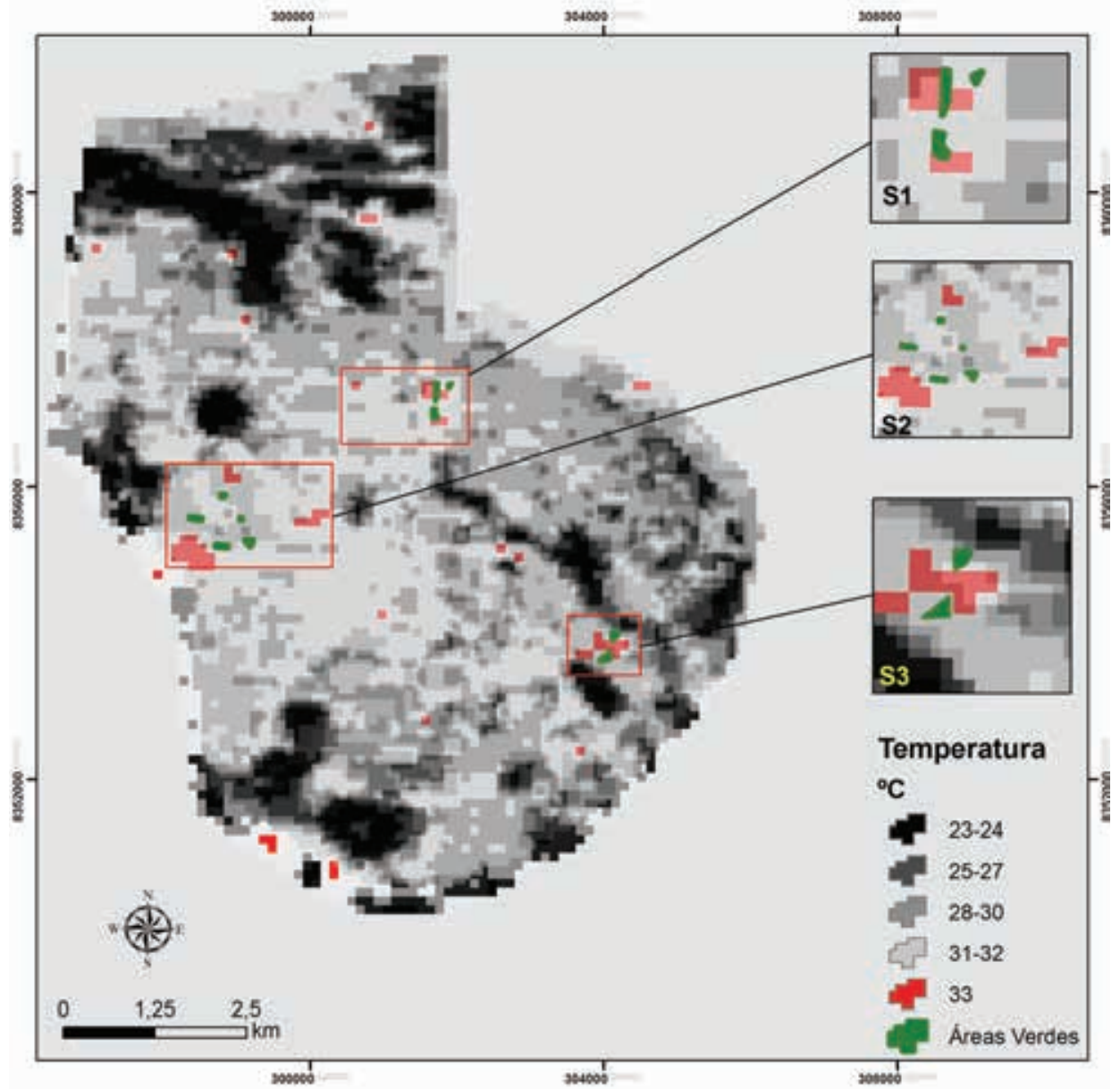

Figura 7. Proposta de novas áreas verdes 


\section{CONSIDERAÇÕES FINAIS}

O método apresentado que intercala o uso de ferramentas de Sistemas de Informações Geográficas e sensoriamento remoto apresentaram eficácia e simplicidade de operação na identificação de ilhas urbanas de calor, e pode ser empregado em qualquer cidade que apresente características para formação de pontos de temperaturas elevadas.

A identificação das sete ilhas de calor urbanas em Vitória da Conquista, a partir de técnicas de SIG, apresentou-se totalmente condizentes com as características ambientais dos locais visitados em campo. Ou, de outro ponto de observação metodológica, pode-se afirmar que as ilhas consolidaram a ocorrência de temperaturas elevadas em tais locais, muita das vezes percebidas pela população e discutida de forma empírica.

Segundo a análise do perfil longitudinal da temperatura observada, quanto maior o aglomerado urbano, como é o caso das grandes capitais do mundo, maior a probabilidade de encontrar pontos quentes em sua paisagem atmosférica, especificamente mais ao centro das cidades. Nota-se, a partir de diversos trabalhos citados e também dos resultados apresentados, que as diversas ocorrências de ilhas de calor urbanas estão intrinsecamente atreladas a zonas consideradas de paisagem urbana com ausência de quaisquer elementos naturais que restabeleçam um microclima local.

Os locais propostos para a criação de áreas verdes revelaram-se, de forma geral, relativamente próxima as ilhas de calor e podem promover mitigação no efeito de temperaturas elevadas. Mesmo no local S2, onde as áreas propostas não se encontram sobre os pontos quentes, sua implementação auxiliaria para minimizar os efeitos da poluição atmosférica.

Este trabalho disponibiliza informações que, se aproveitadas por diversos órgãos que organizem os espaços urbanos, amenizariam problemas de desconforto térmico de onde deriva diversos outros agravantes, como o impacto na saúde populacional para residentes e trabalhadores (como no caso da ilha de calor sobreposta a pátios comerciais) e saúde ambiental de forma geral. 


\section{AGRADECIMENTOS}

A Fundação de Amparo a Pesquisa do Estado da Bahia - Fapesb pelo financiamento; ao Programa de Doutorado em Meio Ambiente e ao Laboratório de Climatologia da UESC, pela disponibilidade de infraestrutura para estudos atmosféricos.

\section{REFERÊNCIAS}

BARCZAK, R.; DUARTE, F. 2012. Impactos ambientais da mobilidade urbana: cinco categorias de medidas mitigadoras. Revista Brasileira de Gestão Urbana, v. 4, n.1, p. 13-32,

BOSCHETTI, L. Modis- Landsat fusion for large area $30 \mathrm{~m}$ burned area mapping. Remote Sensing of Environment, v. 1, p. 33-47, 2015.

BURGESS, J.; HARRISON, C. M.; LIMB, M. People, Parks and the Urban Green: a study of popular meanings and values for open spaces in the city. Urban Studies, v. 25, p. 455-473. 1988.

CARNAHAN, W. H.; LARSON, R. C. An analysis of an Urban Heat Sink. Remote Sensing of Environment, v. 33, n. 1, p. 65-71, 1990.

CARRUS, G. Relations between naturalness and perceived restorativeness ofdifferent urban green spaces las relaciones entre la naturalidad y el poten-cial restaurador percibido de diferentes zonas verdes urbanas. Psyecology, v. 4, p. 227-244, 2013.

CARRUS, G.; PASSAFARO, P.; BONNES, M. Ambientalismo, Etnocentrismo e Dautoritarismo: una scala di atteggiamento verso il verde urbano. Bollettino di Psicologia Applicata, v. 242, p. 3-12, 2004.

CAVALHEIRO, F.; DEL PICCHIA, P. C. D. Áreas verdes: conceitos, objetivos e diretrizes para o planejamento. In: CONGRESSO BRASILEIRO SOBRE ARBORIZAÇÃO URBANA, 1., ENCONTRO NACIONAL SOBRE ARBORIZAÇÃO URBANA, 4., Anais... Vitória, ES, 1992. p. 29-38. 
CIFUENTES, L. Assessing the health benefits of urban air pollution reductions associated with climate change mitigation (2000-2020): Santiago, São Paulo, Mexico city, and New York City. Environmental Health Perspectives, v. 109, sup. 2, 2001.

GARSKE, T.; FERGUSON, N.; GHANI, A. Estimating air temperature and its influence on malaria transmission Across Africa. Plosone, v. 8, n. 2, p. 64-87, 2013.

GEORGE, P. Geografia urbana. São Paulo: Difel, 1983.

GUZZO, P. Cadastro Municipal de Espaços Livres Urbanos de Ribeirão Preto (SP): Acesso Público, Índices e Base para Novos Instrumentos e Mecanismos de Gestão. Revista da Sociedade Brasileira de Arborização Urbana, v.1, n.1, 2006.

HARVELL, C. Climate Warming and Disease Risks for Terrestrial and Marine Biota. Science, v. 296, n. 5576, p. 2158-2162, 2002.

KATSOUYANNI, K. Evidence for interaction between air pollution and high temperature in the causation of excess mortality. Archives of Environmental Health: an International Journal, v. 48, n. 4, p. 235-242, 1993.

KIMURA, F.; TAKAHASHI, S. The Effects os Land-Use and Anthropogenic Heating on the Surface Temperature in the Tokyo Metropolitan Area: A Numerical Experiment. Atmospheric Environment, v. 25B, n. 2, p. 155-164, 1991.

KOKEN, P.; PIVER, W.; YE, F.; ELIXHAUSER, A.; OLSEN, L.; PORTIER, C. Temperature, air pollution, and hospitalization for cardiovascular diseases among elderly people in Denver. Environmental Health Perspectives, v. 111, n. 10, p. 1312-1317, 2003.

KOPPEN, W. das. Geographisca system der klimate, in: handbuch der klimatologie. [s.l.]: Koppen, W. and Geiger, G. 1948. p. 1- 44.

KUHN, K.; CAMPBELL, D.; DAVIES, C. A continental risk map for malaria mosquito (diptera: culicidae) vectors in Europe. Journal of Medical Entomolog y, v. 39, n. 4, p. 621-630, 2002. 
LAAIDI, K. The impact of heat islands on mortality in Paris during the august 2003 heat wave. Environmental health perspectives, v. 120, n. 2, p. 254-259, 2012.

LOBODA, C. R.; ANGELIS, B. L. D. Áreas públicas urbanas: conceito, uso e funções. Ambiência, Guarapuava, PR, v.1 n.1, p. 125-139, jan./jun. 2005.

LOMBARDO, M. A. Ilha de calor nas metrópoles: o exemplo de São Paulo. São Paulo: São Paulo, Hucitec, 1985. 100p.

MARKHAM, B. L.; BARKER. L. Landsat mss and tm post-calibration dynamic ranges, exoatmospheric reflectances and at-satellite temperatures. Earth Observation Satellite. Unites States: Landsat Tech, 1986.

MIHALAKAKOU, G.; SANTAMOURIS, M. Simulation of the Urban Heat Island Phenomenon in Mediterranean Climates. Pure and Applied Geophysics, v.161, p. 429-451, 2004.

MILANO, M. S. Arborização urbana. In: UNIVERSIDADE Livre do meio Ambiente. Curso Sobre Arborização Urbana. Curitiba, 1995.

NICHOL, J.E. A GIS - Based Approach to Microclimate Monitoring in Singapore's High-Rise Housing Estates. Photogrammetric Engineering \& Remote Sensing, v.60, n. 10, p. 1225-1232, 1994.

PADILLA, M. Comparing the accuracies of remote sensing global burned area products using stratified random sampling and estimation. Remote Sensing of Environment, v. 1, p. 46-67. 2015.

PIMENTEL, D.; BURGS, M. World Human Population Problems. In: REFERENCE Module. Earth Systems and Environmental Sciences, 2015. p. 122-142.

SANTANA, N.C. Investigação de ilhas de calor em Brasília: análise multitemporal com enfoque na cobertura do solo. Revista Brasileira de Geografia Física, v.07, n. 6, p. 1044-1054, 2014. 
SOUSA, S. B. Temperatura superficial: procedimentos e técnicas utilizadas para processar e gerar dados de temperatura superficial terrestre $\left({ }^{\circ} \mathrm{C}\right)$ para o município de Goiânia-GO. Laboratório de Processamento de Imagens e Geoprocessamento, 2012. (Texto Explicativo).

VAN, T. T.; BAO, H. D. X. Study of the Impact of Urban Development on Surface Temperature Using Remote Sensing in Ho Chi Minh City, Northern Vietnam. Geographical Research, v.48, p. 1, p. 86-96. 2010.

VIEIRA, P. B. H. Uma visão geográfica das áreas verdes de Florianópolis, SC: estudo de caso do Parque Ecológico do Córrego Grande (PECG). 2004. Trabalho de Conclusão de Curso (Monografia) - Universidade Federal de Santa Catarina, Florianópolis, SC, 2004.

VITÓRIA DA CONQUISTA. Lei ${ }^{\circ}$. 1324. Normas e Diretrizes do Desenvolvimento Urbano do Município de Vitória da Conquista. Vitória da Conquista: Jornal Oficial, 20 dez. p. 1-8. 2000.

Recebido em: 30 de junbo de 2015 Aceito em: 19 de julbo de 2016 